\title{
Formulation and evaluation of buccal films of piroxicam co-crystals
}

\author{
Anand Ammanage, Paul Rodriques, Amolkumar Kempwade* and Ravindra Hiremath
}

\begin{abstract}
Background: The aim of the present study was to enhance the solubility of piroxicam (BCS class II drug) using cocrystallization technique and formulate the buccal films of selected co-crystals for improved therapeutic utilization of drug. Co-crystals of drug with various co-formers (molar ratio 1:1) were prepared by solvent evaporation method and were screened for their aqueous solubility and percent drug content. The formation of co-crystals was confirmed by FTIR, DSC and XRD. Piroxicam co-crystals loaded buccal films were prepared and evaluated for in vitro drug release, ex vivo drug permeation while safety of formulation was determined by histopathological study.

Results: The co-crystals prepared with different co-formers have proved their potential to improve the solubility of the drug. Co-crystals of piroxicam-sucralose have shown six-folds more solubility than parent drug. FTIR analysis indicated shifting in characteristics peaks of piroxicam. DSC analysis showed an extra exothermic peak and alteration in characteristic endothermic peak. The powder $x$-ray diffraction pattern exhibited changes in $2 \theta$ values of intense peaks. Thus, formation of co-crystal was confirmed. Physical characters of buccal films were found to be within limits. Formulation F6 showed highest mucoadhesive strength (5617 \pm 636 dynes $/ \mathrm{cm}^{2}$ ) while formulation F2 showed highest in vitro drug release after 8 h, i.e., $94.557 \%$. The ex vivo drug permeation of F2 was found to be $84.74 \%$. The hisopathological study revealed that there was no damage to buccal mucosal tissue and was found to be intact.
\end{abstract}

Conclusion: The piroxicam-suralose co-crystals based mucoadhesive films of piroxicam could be a better formulation approach with improved solubility, safety, and therapeutic efficacy as compared to conventional tablets.

Keywords: Piroxicam, Sucralose, Co-crystals, Mucoadhesive, Buccal film

\section{Background}

Solubility is one of the major physicochemical properties which affect the therapeutic efficacy of any drug entity. Among the present new drugs available, approximately $8 \%$ possesses high solubility and permeability. Almost $50 \%$ of API's face the problem of diminished efficacy due to poor solubility. Hence, solubility and dissolution becomes prime concern in formulation development [1]. Drug polymer complex, emulsification, micronisation, salt formation, use of co-solvents are various approaches adopted to overcome the problem of solubility [2,3].

Many APIs are in the form of molecular crystals. Normally, solubility of the amorphous form is more as

* Correspondence: kempwadeamol@rediffmail.com

KLES College of Pharmacy, Akkol Road, Nipani, Karnataka 591237, India compared to crystalline form. Co-crystals are basically molecular complexes resulting from hydrogen bonding between co-former and drug. The physicochemical properties of the drug molecule are modified once it gets converted into co-crystal but its intrinsic activity is preserved. Thus co-crystals of many class II drugs have shown improved dissolution rate (comparable to amorphous form) and long term chemical and physical stability [4-6].

Piroxicam being highly potent NSAID preferred in various inflammatory conditions, osteoarthritis and rheumatoid arthritis. Oral administration of piroxicam is associated with adverse effects such as ulcerative colitis, GI irritation and peptic ulcers whereas severe pain and inflammation is observed with parenteral at injection 
site. Other major drawback is poor solubility of piroxicam (BCS class II drug). After its oral administration, almost $2 \mathrm{~h}$ are required to exert its therapeutic effect. In such cases for such class of drugs (analgesics), enhanced bioavailability with rapid onset of action is essential $[7,8]$.

When it comes to administration of drug, we do have numerous routes of administration, among which oral route of administration is found to be more convenient and most preferred. However, oral route of administration is associated with some undesired effects such as first pass metabolism and enzyme mediated degradation in GI tract leading to loss of drug. Due to this oral administration becomes a limiting factor for some drugs. As an alternative, drug-loaded buccal patches is found to be a highly acceptable means of drug administration by patients. It offers increased contact hour and higher flux of drug delivery system leading to improved patient compliance. Further systemic perfusion to the oral mucosa is comparatively higher than other mucosal layers which have added advantage for rapid drug absorption $[9,10]$.

Oral route of administration in the form of "buccal patch" has proved to be a promising alternative to other routes of administration. The route protects the drug from hepatic first pass effect, degradation of drug in GI, thereby allowing the drug to enter directly systemic circulation. Moreover, advantages such as ease of administration, removal of administered patches are associated with buccal patches [11].

In present study, an attempt was made to prepare the co-crystals of piroxicam using different conformers to enhance its solubility, further loading of thus formed cocrystals into buccal patches was done and evaluation for their in vitro drug release profile and ex vivo permeation was carried out.

\section{Materials}

Piroxicam was obtained as a gift sample from Zydus Cadila Pvt Ltd, Goa. Sucralose was procured from Ozone Pvt Ltd. Other excipients were procured from verified suppliers. All the solvents and reagents used were of analytical grade.

\section{Methods}

\section{Synthesis of co-crystals}

The co-crystals of piroxicam with various co-formers (viz. sucralose, dioxane, oxalic acid, Malonic acid, caprylic acid, fumaric acid, adipic acid, benzoic acid, and xylitol) were synthesized by solvent evaporation method as described by Prasad RV et al. Briefly, piroxicam and co-formers were taken on the basis of their molecular weight in 1:1 ratio and mixed completely using acetone. The mixture was kept aside overnight in order to remove the solvent completely. The obtained product was ground to get a freely flowing powder. The solubility of resulting co-crystals was determined and selected coformer (co-crystal showing highest solubility) was further screened in order to select optimum ratio of drug and co-former. Three ratios of drug: co-former were screened viz $(1: 0.5,1: 1,1: 2)$ [12-14].

\section{Characterization of co-crystals Melting point determination [15]}

Melting points of co-crystals were determined using capillary method where co-crystals were placed in the capillary tube fused at one end tied to thermometer. The thermometer was dipped in Thiele's tube containing paraffin oil. The tube was heated with the help of burner and the melting point was noted when the co-crystal just started melting.

\section{Saturation solubility determination [16]}

Solubility was determined by dispersing co-crystals corresponding to $100 \mathrm{mg}$ of piroxicam in volumetric flask containing $100 \mathrm{ml}$ of water. The volumetric flask is subjected to agitation using rotary shaker for $24 \mathrm{~h}$. The solution is further diluted suitably with water and analyzed by UV spetroscopically (Shimadzu UV-1700) at $354 \mathrm{~nm}$.

\section{Drug content determination [1, 17]}

The accurately weighed co-crystals equivalent to $10 \mathrm{mg}$ of the drug was dissolved in $100 \mathrm{ml}$ of distilled water. The solution was filtered through a filter paper. Ten milliliters of filtrate was withdrawn from the above solution and diluted to $100 \mathrm{ml}$ with water. The absorbance of the corresponding solution was taken at $354 \mathrm{~nm}$ and concentration was calculated. The drug content was calculated by using previously validated calibration curve.

\section{IR spectroscopy [15]}

IR spectrum of the drug, co-former, and co-crystals were recorded using FTIR (Bruker tensor II, Germany and Shimadzu IRAffinity-1S, Japan) in order to determine predictable interaction between the drug and co-former. The co-crystals were mixed with potassium bromide $(\mathrm{KBr})$ and then pressed with hydraulic press to form pellets which were further subjected to scanning in between 4000 and $400 \mathrm{~cm}^{-1}$.

\section{DSC analysis [15]}

Thermal behavior of the drug, co-former, and their cocrystals was studied using differential scanning calorimeter (Shimadzu DSC-60, Japan). The small quantity of sample was crimped between the aluminum pans using hydraulic press. The pans were heated at the rate of 5 ${ }^{\circ} \mathrm{C} / \mathrm{min}$ from 0 to $300{ }^{\circ} \mathrm{C}$ in the presence of nitrogen gas. 


\section{Powder X-ray diffraction [15]}

Powder $\mathrm{x}$-ray diffraction is an important tool for prediction of crystalline nature of any substance. This is possible because individual substance shows different diffractogram. Diffractograms of pure drug, co-former and co-crystal were obtained using powder X-ray diffractometer (Ragaku miniflex-600 X-ray diffractometer, Japan).

\section{Formulation of piroxicam co-crystals incorporated buccal film [18] (Procedure)}

The films containing piroxicam co-crystals were prepared using different ratios of sodium hydroxypropyl cellulose, chitosan and carbopol 934. Chitosan was dispersed and stirred in $1 \%$ glacial acetic acid solution until a clear solution $(0.1 \% \mathrm{w} / \mathrm{v})$ is obtained. Carbopol 934 was soaked in water for an hour to get $0.1 \% \mathrm{w} / \mathrm{v}$ dispersion. HPMC K4M was soaked in 95\% ethanol to get $0.5 \% \mathrm{w} / \mathrm{v}$ dispersion. These polymeric dispersions were mixed gradually in a quantity as mentioned in Table 1 for an hour in $95 \%$ ethanol to get bubble free dispersion. Then the weighed quantity of piroxicam co-crystals were added slowly in the polymeric solution and stirred on the magnetic stirrer to obtain a uniform distribution of the drug. The quantity of material to be taken is decided on the basis of surface area of the petridish. Glycerol was added as plasticizer. The solution was poured in circular dish. The films were dried for $2 \mathrm{~h}$ at room temperature. Then they were further dried at $40{ }^{\circ} \mathrm{C}$ in hot air oven for $24 \mathrm{~h}$. These were then kept in vacuum desiccator for further drying. Various formulations prepared were as shown in Table 1.

\section{Evaluation of buccal film}

\section{Thickness and weight variation [19]}

Thicknesses of 10 films were measured using digital vernier caliper, and their mean value was taken. The results were expressed in mean \pm standard deviation (SD). Weights of 10 films were measured on digital balance and their mean value was expressed as mean \pm standard deviation (SD).

\section{Percentage moisture loss [20]}

Weighed films were kept in desiccators containing anhydrous calcium chloride and reweighed after 3 days. The \% moisture loss was calculated using following formula.

$$
\begin{aligned}
\text { Percent moisture loss }= & \frac{\text { Initial weight-Final weight }}{\text { Initial weight }} \\
& \times 100
\end{aligned}
$$

\section{Percentage moisture uptake [21]}

Films were kept in desiccators containing saturated aluminum chloride solution and reweighed after 3 days. The $\%$ moisture uptake was calculated using formula.

$$
\text { Percent moisture uptake }=\frac{\text { Final weight-Initial weight }}{\text { Initial weight }} \times 100
$$

\section{Drug content [21]}

It is determined by UV spectroscopic method wherein a film containing piroxicam co-crystals equivalent to 10 $\mathrm{mg}$ of drug was chopped and dissolved in $100 \mathrm{ml}$ of $\mathrm{pH}$ 6.8 buffer in a $100 \mathrm{ml}$ volumetric flask. The solution is filtered through $0.4 \mathrm{~mm}$ filter paper and from the same solution $10 \mathrm{ml}$ is diluted and absorbance was measured at $354 \mathrm{~nm}$.

\section{Folding endurance [21]}

A specific area of strip was cut and repeatedly folded at the same place till it broke. The number of times the film could be folded without breaking is considered as folding endurance.

\section{Tensile strength}

It is the maximum stress applied at which the film breaks. In order to determine the elongation as a tensile strength, the polymeric film was pulled by means of pulley system; weights were gradually added to the pan to increase the pulling force till the film was broken. Elongation of the film was noted with the help of magnifying glass. It is expressed in terms of $\mathrm{kg} / \mathrm{cm}^{2}$. The tensile strength was calculated by using formula.

Table 1 Formulation of buccal film F1 to F6

\begin{tabular}{lllllll}
\hline Formulation code & HPMC & $\begin{array}{l}\text { Chitosan } \\
(0.5 \% \mathrm{w} / \mathrm{v})(\mathrm{ml})\end{array}$ & $(0.1 \% \mathrm{w} / \mathrm{v})(\mathrm{ml})$ & $\begin{array}{l}\text { Carbopol } \\
(0.1 \% \mathrm{w} / \mathrm{v})(\mathrm{ml})\end{array}$ & $\begin{array}{l}\text { Glycerol } \\
(\mathrm{ml})\end{array}$ & $\begin{array}{l}\text { Piroxicam co-crystals } \\
(\mathrm{mg})\end{array}$ \\
\hline F1 & 1 & 1 & - & 0.1 & 22 & $\begin{array}{l}95 \% \text { ethanol } \\
(\mathrm{ml})\end{array}$ \\
F2 & 2 & 2 & - & 0.1 & 22 & 7.9 \\
F3 & 3 & 3 & - & 0.1 & 22 & 3.9 \\
F4 & 1 & - & 1 & 0.1 & 22 & 7.9 \\
F5 & 2 & - & 2 & 0.1 & 22 & 5.9 \\
F6 & 3 & - & 3 & 0.1 & 22 & 3.9 \\
\hline
\end{tabular}




$$
S=\frac{m \times g}{b \times t}
$$

Where $S$ is tensile strength, $m$ is mass in grams, $g$ is acceleration due to gravity, $b$ is breadth in $\mathrm{cm}$, and $t$ is thickness

\section{Percent swelling index}

The polymeric films of $1 \mathrm{~cm}$ diameter were weighed accurately and kept immersed in $50 \mathrm{ml}$ of water. The films were taken out carefully at 5, 10, 30, and 60 min intervals and blotted with filter paper to remove the water present on their surface and weighed accurately, the percent swelling is calculated using formula.

$$
\text { Percent swelling index }=\frac{\text { Final weight-Initial weight }}{\text { Final weight }} \times 100
$$

\section{Surface $p H$ [21]}

The combined glass electrode was used for determination of surface $\mathrm{pH}$. The films were kept in contact with distilled water for $1 \mathrm{~h}$ in glass tubes. The surface $\mathrm{pH}$ was then noted by bringing a single glass electrode near the surface of film and allowing it to equilibrate for $1 \mathrm{~min}$.

\section{Mucoadhesive strength [22, 23]}

Mucoadhesive strength of the film was determined by using pan balance. Section of goat buccal mucosa was obtained from a local slaughter house and was used within $2 \mathrm{~h}$ of slaughtering. The required mucosal membrane was cut and washed with distilled water and then with phosphate buffer of $\mathrm{pH}$ 6.8. The two pieces of mucosal membranes were tied to two different slides with thread. One slide was then fixed to underneath portion of pan and second slide was fixed to wooden board of pan balance such that mucosal membranes would face towards each other. The film was placed in between these two membranes and little force is applied for 1 min. Dummy granules were then added in another pan until the slides get detached from each other. The weight of granules that detaches slides apart was recorded and mucoadhesive strength was calculated using formula as follows:

$$
\text { Mucoadhesive strength }\left(\text { dynes } / \mathrm{cm}^{2}\right)=\frac{m \times g}{A} \times 100
$$

Wherein $m=$ weight of granules, $g=$ acceleration due to gravity, $A=$ area of mucosa exposed

\section{In vitro drug release study [24]}

In vitro drug release from buccal patch was studied by using Franz diffusion cell assembly (PermeGear, Inc. Hellertown, PA, USA). Buffer solution of $\mathrm{pH} 6.8$ was added into the receptor chamber. Buccal film of $1 \mathrm{~cm}$ diameter containing $10 \mathrm{mg}$ of drug was placed in donor compartment. Both the compartments were separated by dialysis membrane (Mol. wt 12000-14000) which was previously soaked in receptor medium for $2 \mathrm{~h}$. Care was taken for the absence of air bubble between membrane and liquid surface for avoiding any disruption in between the process. The temperature of the receptor medium was maintained at $37 \pm 1{ }^{\circ} \mathrm{C}$ during whole study by circulating water bath (Thermofisher Scientific, India). $0.5 \mathrm{ml}$ of sample was withdrawn at predetermined time intervals from receptor compartment and replaced with fresh buffer till $8 \mathrm{~h}$. The samples were diluted suitably and analyzed spetroscopically at $354 \mathrm{~nm}$. The amount of drug release was determined by using previously validated calibration curve. The flux value was determined by using following formula

$$
\text { Flux }=\frac{\text { Amount of drug released }(\mathrm{mg})}{\operatorname{Time}(\mathrm{hr}) \times \operatorname{Area}\left(\mathrm{cm}^{2}\right)}
$$

\section{Ex vivo drug permeation study [25]}

This study was done in the same manner as described under in vitro drug release study. In this study, dialysis membrane was replaced with buccal tissue of goat, which was obtained from local slaughter house immediately after its slaughtering. It was then carefully brought to laboratory by keeping it in phosphate buffer solution of $\mathrm{pH}$ 6.8. Buccal membrane was separated from underlying membrane without damage using a sharp knife. The membrane was placed between the donor and receptor compartment. The film of $1 \mathrm{~cm}$ diameter containing $10 \mathrm{mg}$ of piroxicam was placed in the donor compartment. The temperature of the Franz diffusion cell was maintained at $37 \pm 1{ }^{\circ} \mathrm{C}$. Saline phosphate $\mathrm{pH}$ 6.8 was used as receptor medium. The sampling was done at predetermined time interval for $8 \mathrm{~h}$ and amount of drug permeated was analyzed by UV spectrophotometer at $354 \mathrm{~nm}$.

\section{Histopathological evaluation of buccal mucosa}

Histopathological evaluation of buccal mucosa was carried out to check any cellular damage occurred due to the film during ex vivo drug permeation study. The buccal mucosa previously used for ex vivo was taken for the study and was compared with the mucosa which was incubated in PBS ( $\mathrm{pH}$ 6.8). The tissue was fixed on glass slide by using $10 \%$ buffered formalin. Paraffin section were cut on glass slides and stained with hematoxylin and eosin. These sections were examined under light microscope by a pathologist who was unaware of the study, to detect any damage to tissue during ex vivo drug permeation. 
Table 2 Melting point, solubility, and \% drug content of co-crystals

\begin{tabular}{llllll}
\hline Sr. no. & Drug/co-former & Melting point of single entity & Co-crystal melting point (1:1) & Solubility (mg/100ml) & \% drug content \\
\hline 1 & Piroxicam & $206-208{ }^{\circ} \mathrm{C}$ & - & $10.73 \pm 0.985$ & - \\
2 & Piroxicam-sucralose & $125^{\circ} \mathrm{C}$ & $186^{\circ} \mathrm{C}$ & $60.73 \pm 1.95$ & 98.37 \\
3 & Piroxicam-dioxane & $11.8^{\circ} \mathrm{C}$ & $178{ }^{\circ} \mathrm{C}$ & $34.22 \pm 3.56$ & 95.66 \\
4 & Piroxicam-oxalic acid & $189^{\circ} \mathrm{C}$ & $230{ }^{\circ} \mathrm{C}$ & $32.52 \pm 2.21$ & 95.86 \\
5 & Piroxicam-malonic acid & $135.6{ }^{\circ} \mathrm{C}$ & $165^{\circ} \mathrm{C}$ & $42.84 \pm 2.82$ & 96.30 \\
6 & Piroxicam-caprylic acid & $16.7{ }^{\circ} \mathrm{C}$ & $186^{\circ} \mathrm{C}$ & $38.20 \pm 1.21$ & 98.96 \\
7 & Piroxicam-fumaric acid & $287^{\circ} \mathrm{C}$ & $194^{\circ} \mathrm{C}$ & $37.62 \pm 3.61$ & 97.93 \\
8 & Piroxicam-adipic acid & $152^{\circ} \mathrm{C}$ & $196{ }^{\circ} \mathrm{C}$ & $34.14 \pm 4.50$ & 99.39 \\
9 & Piroxicam-benzoic acid & $122^{\circ} \mathrm{C}$ & $180^{\circ} \mathrm{C}$ & $32.55 \pm 2.43$ & 96.50 \\
10 & Piroxicam-xylitol & $92{ }^{\circ} \mathrm{C}$ & $196{ }^{\circ} \mathrm{C}$ & $35.68 \pm 7.81$ & 96.55 \\
\hline
\end{tabular}

\section{Stability studies}

Stability studies were performed to check any considerable changes that may occur in formulation during its storage. All the formulations were kept for 3 months in triplicate at $40^{\circ} \pm 2^{\circ} \mathrm{C}$ and $75 \% \pm 5 \% \mathrm{RH}$ in stability chamber. Stability of the formulations was evaluated by determining their folding endurance, drug content and in vitro drug release.

\section{Results}

Selection of suitable Co-former for any API is most vital step in the synthesis of co-crystal. Various knowledge as well as experimental based models are available, but hit and trial approach is most widely practiced by researchers. In the present study, same approach was utilized for the selection of profound co-former. Piroxicam co-crystals were synthesized by using 9 different coformers and solubility of the co-crystals was determined. All the co-crystals have shown increase in the solubility of the drug. The highest solubility was observed with the co-crystals of Sucralose $(60.73 \pm 1.95 \mathrm{mg} / 100 \mathrm{ml})$, comprising 6 times to that of actual solubility of the bulk drug. Hence, sucralose was selected for further study. The sweet taste of sucralose offers added advantage of taste masking which helps during buccal film preparation.

Melting point of drug, co-formers and co-crystals were determined. Melting point of any crystalline chemical entity reveals about purity and crystalline nature of the entity. The melting points of the cocrystals were found to be different from drug as well as corresponding co-former. This reveals the production of new crystalline packing arrangement and formation of co-crystals. This may lead to enhancement of solubility and variation in other physico-chemical properties.

The percentage drug contents of co-crystals were found to be in the range of $95.66 \%$ to $99.39 \%$. The results of solubility, melting point and percent rug content are as shown in Table 2.

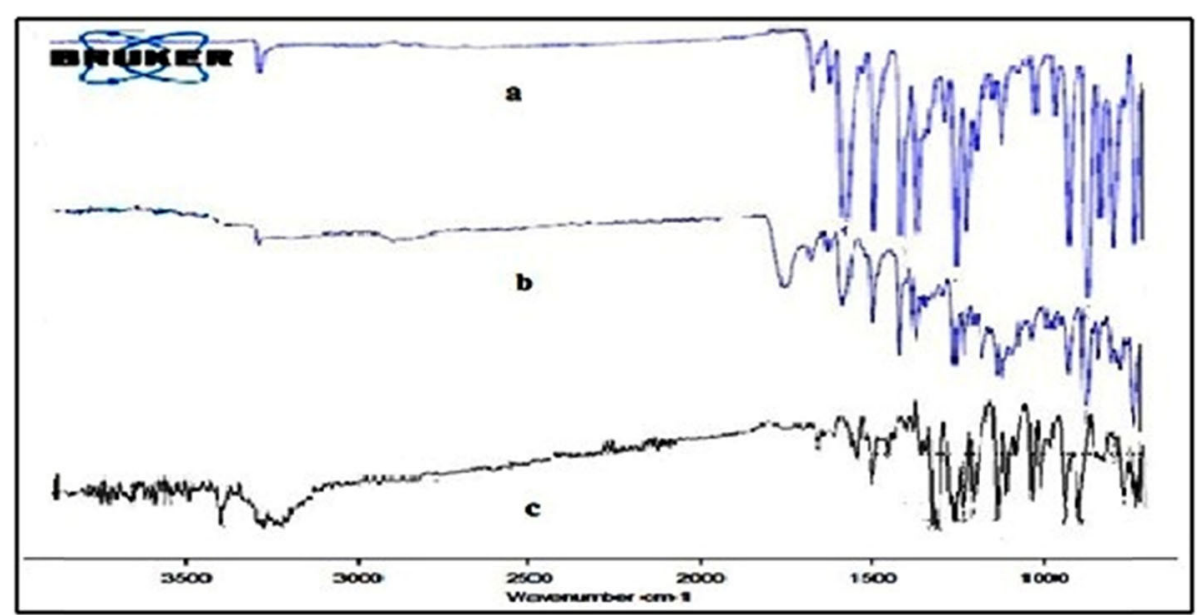

Fig. 1 FTIR spectra of a piroxicam, b physical mixture, and c co-crystal 


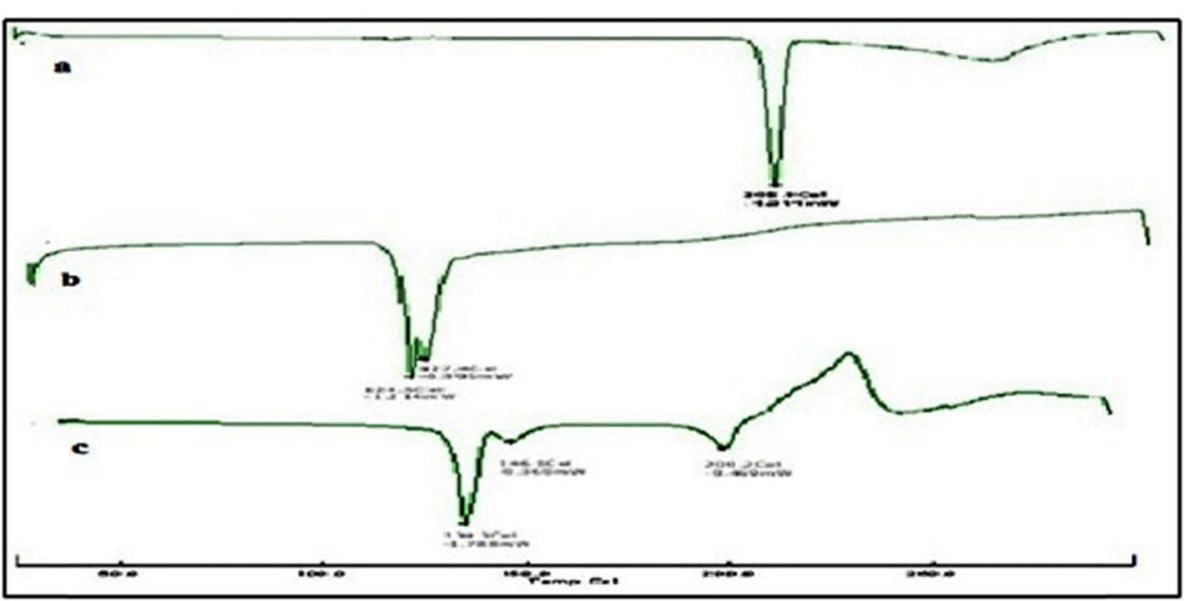

Fig. 2 DSC thermogram of a piroxicam, b sucralose, and c co-crystal

\section{Confirmation of formation of co-crystals FTIR analysis of co-crystals}

The FTIR analysis of the pure drug, physical mixture (drug + sucralose) and co-crystal was done. IR spectra are as shown in Fig. 1. The characteristic peaks of piroxicam and sucralose were found to be remarkably changed in IR spectra of the co-crystal. The peak corresponding to $-\mathrm{NH}_{2}$ group $\left(3351 \mathrm{~cm}^{1}\right)$ was disappeared in the co-crystal spectra

\section{DSC analysis of co-crystals}

Thermal behavior of the drug, sucralose, and co-crystals were studied with the help of DSC. The thermograms obtained are as shown in Fig. 2. Drug has shown sharp endothermic peak at $206^{\circ} \mathrm{C}$ corresponding to its melting point. The sucralose has also shown sharp doublet near $125{ }^{\circ} \mathrm{C}$. The co-crystal obtained has shown changes in the positions of the endotherms. The endothermic peaks were obtained at $200{ }^{\circ} \mathrm{C}, 146{ }^{\circ} \mathrm{C}$, and $134{ }^{\circ} \mathrm{C}$.

\section{Powder X-ray diffraction (PXRD) study}

The PXRD diffractograms for piroxocam, sucralose, and their co-crystal are shown in Fig. 3. The characteristic peaks of piroxicam were observed at their corresponding $2 \theta$ values viz $8.4,14.4,17.4,21.4$, and 27.14. Sucralose has also showed its characteristic peaks at their relative $2 \theta$ values viz $15.2,16.2,19.4,20.2$, and 24.1. Identical results of diffractogram were reported in previous studies. The diffractogram of piroxicam co-crystals was found to be different from its parent material and more numbers

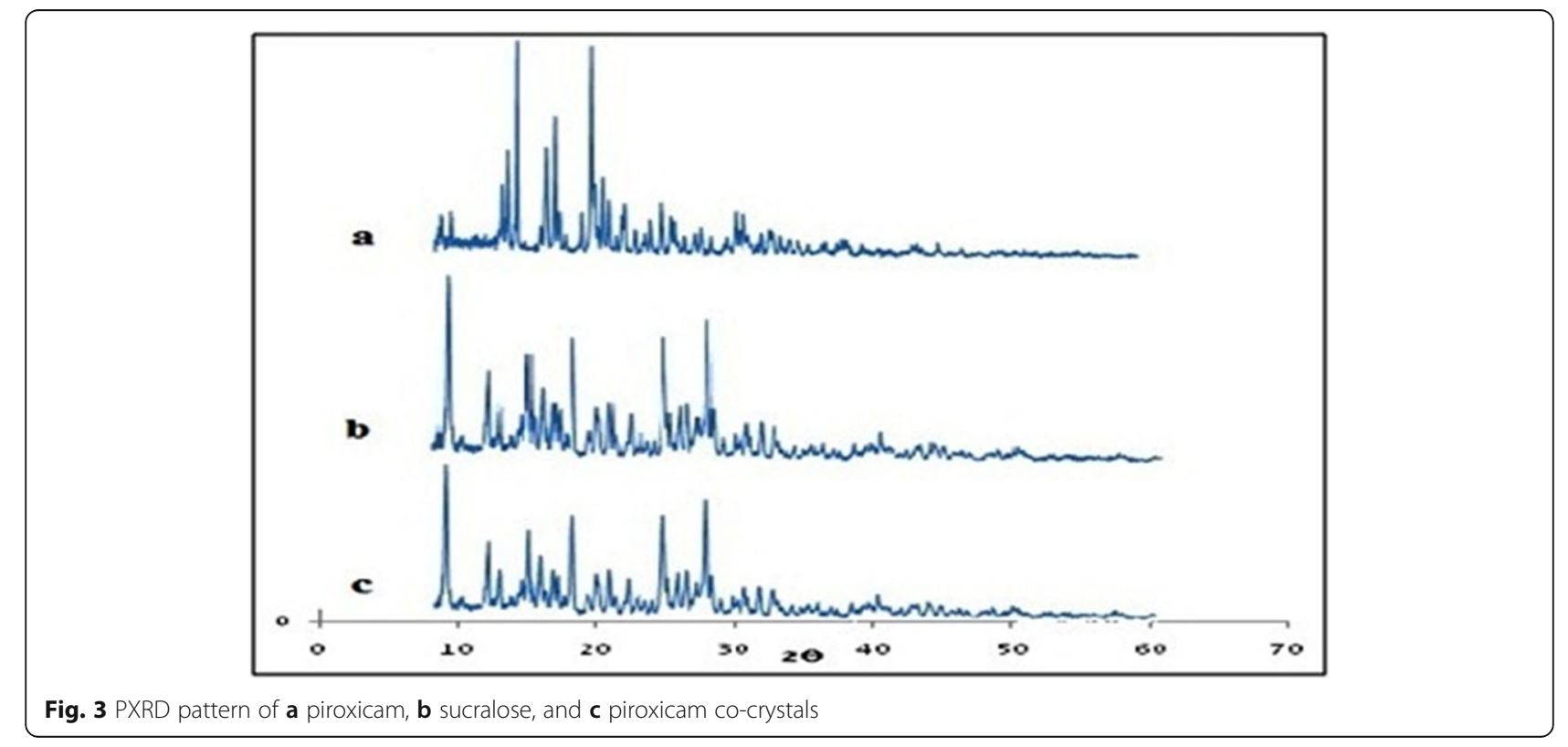




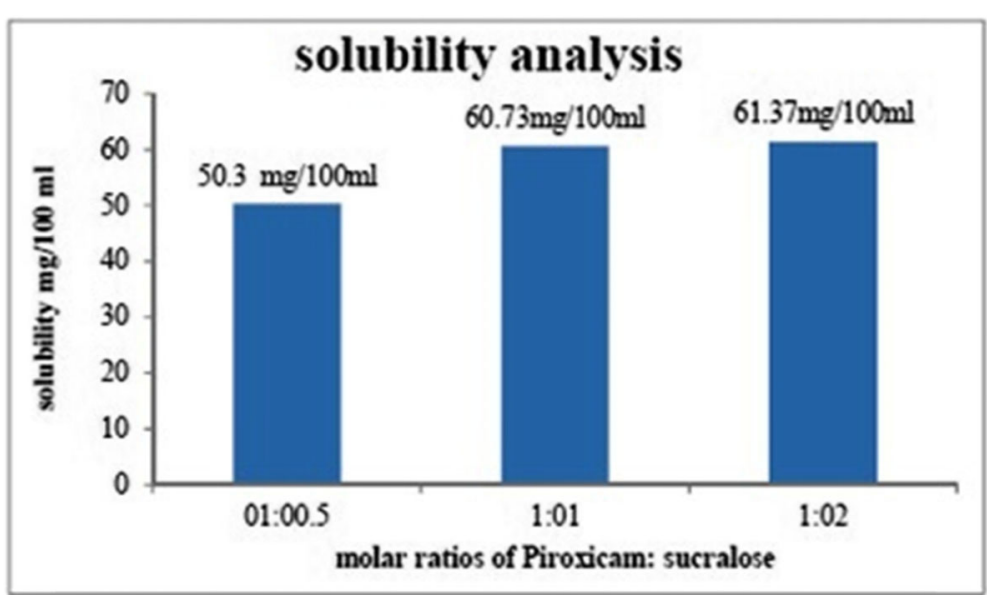

Fig. 4 Results of solubility studies of piroxicam-sucralose co-crystals

of peaks were observed. Various peaks observed for cocrystal were at $2 \theta$ values of $8.5,8.7,11.6,11.7,12.6,14.6$, 17.5, 27.5, 24.3, 24.7, and 27.9.

\section{Solubility analysis for selection of drug-coformer ratio}

Solubility analysis of co-crystals prepared with three different molar ratios of piroxicam:sucralose viz. 1:0.5, 1:1, and 1:2 were carried out and results obtained are as shown in Fig. 4. The 1:1 ratio was selected for further study.

\section{Formulation of mucoadhesive buccal film of piroxicam buccal film}

The buccal films of synthesized co-crystals were prepared by using various polymers as described by Augusthy AR et al. [26]. Preliminary screening was carried out for selection of suitable polymers and their optimum ratios. Based on this screening, HPMC E15, chitosan, and carbopol were selected for film formation. The prepared buccal films were subjected to various evaluation parameters, as summarized in Table 3.
In vitro drug release of films

In vitro drug release studies from all formulations were carried out in phosphate buffer of $\mathrm{pH}$ 6.8. The study was performed for $8 \mathrm{~h}$ and cumulative drug release was calculated at different time intervals. The formulation F2 showed highest drug release of $94.557 \%$ (Fig. 5). The flux values were found to be ranged from 1.277 to $1.441 \mathrm{mg} /$ $\mathrm{h} / \mathrm{cm}^{2}$ as shown in Table 4 .

\section{Ex vivo drug permeation}

Ex vivo drug permeation study was carried out through freshly excised goat buccal mucosa. The formulation F2 which was having maximum drug release after $8 \mathrm{~h}$ was selected for ex vivo permeation study (Table 5). The percent cumulative amount drug permeated in 8 hrs was calculated. The cumulative drug permeation was found to be $84.74 \%$ for formulation F2 after $8 \mathrm{~h}$.

\section{Histopathological study}

The histopathological images of buccal mucosa obtained are as shown in Fig. 6. Collective segments were

Table 3 Evaluation parameters of formulated films of piroxicam co-crystals

\begin{tabular}{|c|c|c|c|c|c|c|}
\hline Parameters & F1 & $\mathrm{F} 2$ & F3 & F4 & F5 & F6 \\
\hline Weight (mg) & $43.94 \pm 5.69$ & $48.44 \pm 4.57$ & $65.02 \pm 8.73$ & $46.74 \pm 6.12$ & $54.89 \pm 4.16$ & $68.45 \pm 5.69$ \\
\hline Thickness (mm) & $0.112 \pm 0.04$ & $0.148 \pm 0.03$ & $0.213 \pm 0.03$ & $0.138 \pm 0.02$ & $0.196 \pm 0.05$ & $0.235 \pm 0.06$ \\
\hline$\%$ Drug content & $94.88 \pm 0.14$ & $96.86 \pm 0.08$ & $94.94 \pm 0.17$ & $96.88 \pm 0.08$ & $94.88 \pm 0.12$ & $93.15 \pm 2.90$ \\
\hline$\%$ moisture uptake & $15.807 \pm 6.85$ & $9.633 \pm 3.25$ & $11.61 \pm 2.32$ & $12.6 \pm 42$ & $13.553 \pm 3.9$ & $12.89 \pm 4.2$ \\
\hline$\%$ moisture loss & $4.76 \pm 2.38$ & $5.29 \pm 1.47$ & $11.3 \pm 0.86$ & $8.27 \pm 3.81$ & $3.74 \pm 2.38$ & $5.96 \pm 2.63$ \\
\hline Surface $\mathrm{pH}$ & $6.61 \pm 0.03$ & $6.38 \pm 0.07$ & $6.82 \pm 0.03$ & $6.82 \pm 0.06$ & $6.76 \pm 0.07$ & $6.29 \pm 0.07$ \\
\hline Folding endurance & $256.33 \pm 1.46$ & $285.66 \pm 2.08$ & $290.10 \pm 1.00$ & $286.66 \pm 2.56$ & $296.66 \pm 1.52$ & $274.40 \pm 2.00$ \\
\hline Mucoadhesive strength $\left(\right.$ dyne $\left./ \mathrm{cm}^{2}\right)$ & $3760 \pm 273$ & $4685 \pm 450$ & $5033 \pm 530$ & $4828 \pm 452$ & $5034 \pm 563$ & $5617 \pm 636$ \\
\hline Tensile strength $\left(\mathrm{kg} / \mathrm{cm}^{2}\right)$ & $1.61 \pm 0.01$ & $1.57 \pm 0.03$ & $1.26 \pm 0.01$ & $1.61 \pm 0.01$ & $1.57 \pm 0.031$ & $1.26 \pm 0.01$ \\
\hline \% Swelling index & $12.12 \pm 1.24$ & $14.33 \pm 1.77$ & $20.51 \pm 1.58$ & $16.77 \pm 1.69$ & $17.25 \pm 1.43$ & $23.04 \pm 1.25$ \\
\hline
\end{tabular}




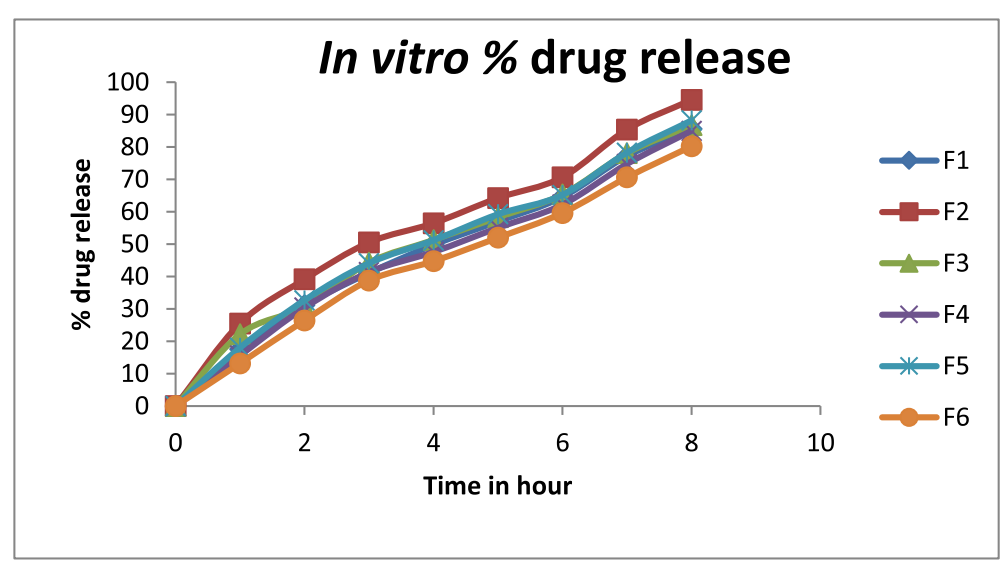

Fig. 5 Graphical representation of in vitro \% cumulative drug release

investigated which have shown normal structure of buccal mucosal membrane. The buccal mucosal tissue which was made to remain in contact with the formulation for $8 \mathrm{~h}$ found to be undamaged and no manifestation of harmful effect was seen as compared to tissue which was placed in phosphate buffer $\mathrm{pH}$ 6.8. Therefore, buccal film of piroxicam co-crystals seems to be safe for administration of formulation via buccal mucosa.

\section{Stability studies}

The formulations were kept for 3 months at $40{ }^{\circ} \mathrm{C} \pm$ $2{ }^{\circ} \mathrm{C}$ and $75 \pm 5 \% \mathrm{RH}$ and checked for its folding endurance, drug content and percent drug release after $8 \mathrm{~h}$. The results have showed negligible changes in the parameters of F1 to F6 after 3 months of storage (Table 6).

\section{Discussion}

Pharmaceutical co-crystal is recently explored as an aspiring approach to enhance the solubility, dissolution rate, and physicochemical stability of API without changing its pharmacological efficacy. It is a multicomponent system wherein two distinct solid substances viz. API and conformer are bound together in stoichiometric ratio by non-covalent interactions. Various research groups have studied and defined co-crystals differently [27-30]. Among available definitions most accepted definition was put forth by a group of 46 scientists during Indo-US Science and Technology Forum sponsored, Indo-US Bilateral Meeting (Delhi-2012) entitled "The Evolving Role of Solid State Chemistry in Pharmaceutical Science." According to them co-crystals are solids that are crystalline single-phase materials composed of two or more different molecular and/or ionic compounds generally in a stoichiometric ratio which are neither solvates nor simple salts. According to a draft of USFDA released in 2013, co-crystals are solids which are crystalline materials composed of two or more molecules in the same crystal lattice (http://www.fda.gov/downloads/ drugs/guidancecompliancergulatoryinformation/guidances/ ucm281764.pdf), [31]. Co-crystals have opened an easiest and economical way to modify the drug properties without use of harsh chemicals and offering high yields.

During the study co-crystals were prepared with various co-formers among which sucralose co-crystals have shown highest improvement in the solubility of drug. Normally, the co-crystal formation involves noncovalent interactions between API and conformer like hydrogen bonding and van der Walls forces. Out of these interactions, hydrogen bonding interactions are most commonly observed. According to graph-set notation system described by Etter, there are three rules for preferable hydrogen bond formation: every acidic hydrogen molecule will involve in hydrogen bond formation,

Table 4 Results of in vitro \% CDR, flux, and release kinetics

\begin{tabular}{llll}
\hline Formulations & \% cumulative drug release in $8 \mathrm{~h}$ & Flux $\left(\mathrm{mg} / \mathrm{h} / \mathrm{cm}^{2}\right)$ & Release kinetics $R^{2}$ \\
\hline F1 & $85.628 \pm 2.54$ & 1.363 & $R^{2}=0.998$ (first order) \\
F2 & $94.557 \pm 3.21$ & 1.441 & $R^{2}=0.994$ (first order) \\
F3 & $86.707 \pm 2.36$ & 1.380 & $R^{2}=0.994$ (first order) \\
F4 & $85.007 \pm 2.87$ & 1.353 & $R^{2}=0.995$ (first order) \\
F5 & $88.197 \pm 3.05$ & 1.404 & $R^{2}=0.996$ (first order) \\
F6 & $80.211 \pm 1.89$ & 1.277 & $R^{2}=0.994$ (first order) \\
\hline
\end{tabular}


Table 5 Result of ex vivo \% cumulative drug permeation and flux

\begin{tabular}{lll}
\hline Formulation & \% Cumulative drug permeation & Flux $\left(\mathrm{mg} / \mathrm{h} / \mathrm{cm}^{2}\right)$ \\
\hline F2 & $84.74 \%$ & 1.349 \\
\hline
\end{tabular}

all hydrogen bond acceptors will be involved in bond formation and best hydrogen donors and hydrogen acceptors will form hydrogen bonds [32]. Thus reason behind improvement in solubility may be attributed to the structure of the sucralose, as it has hydrogen bond donor count of 5 and hydrogen bond acceptor count of 8 which results in more chances of formation of hydrogen bonds and generating co-crystals with enhanced hydrophilic nature (https://pubchem.ncbi.nlm.nih.gov/ compound/71485).

Various studies have described different methods to confirm the formation of co-crystals. These methods utilize different physicochemical properties of co-crystals for confirmation like pKa, Hansen solubility parameter, FTIR, thermal analysis (DSC), PXRD, and solid-state NMR. In the present study, FTIR, DSC, and PXRD analysis of co-crystals were carried out to confirm the synthesis of co-crystals. As reported earlier in results section, the peak corresponding to $-\mathrm{NH}_{2}$ group (3351 $\mathrm{cm}^{-1}$ ) was disappeared in co-crystal spectra. This may be the probable group which is involved in the bond formation with sucralose to synthesize co-crystal. The other peaks were also altered moderately and found to a bit wide in IR spectra of the co-crystal. Similar observations have been observed in earlier studies thus confirm the formation of co-crystal.

DSC thermogram of co-crystal has shown the reduction in the sharpness of peak as well as peak intensity which indicates the probable chances of change in crystalline pattern. Surprisingly, thermogram of co-crystal was also showing one exothermic peak which was absent in drug as well as co-former thermogram. This may be attributed to formation of more stable form of the drug produced after recrystallization. This is in confirmation to the earlier reports wherein 20 drug:co-former systems were analyzed by DSC and all have shown exothermic peaks [33]. Thus presence of exothermic peak is also considered as an indication of formation of co-crystal.

Though single crystal X-ray diffraction (SXRD) is considered as best technique to analyze the crystal at its atomic level, it is highly difficult to get single crystal suitable for SXRD analysis. Thus PXRD is widely used to confirm the co-crystal formation. Reduction in the peak intensity of the co-crystal was observed as compared to the pure drug and sucralose. Further, some intense peaks with different angles other than drug specific angles were observed. The changes in diffraction pattern and increment in number of peaks were reported as an evidence of formation of co-crystals [34]. Thus, disappearance of the characteristic peak in FTIR spectrum, addition of one exothermic peak in thermogram of DSC and increment in number of peaks with different angles other than drug-specific angles in diffractogram has concluded that co-crystals have been successfully synthesized.

The selection of drug: conformer ratio is important in order to avoid the unnecessary excess of the co-former. Solubility was found to be increased significantly with increase in quantity of conformer from 1:0.5 to $1: 1$. However, further increase in co-former (1:2) did not show remarkable improvement in the solubility. This may be due to complete occupancy of all the groups available for binding on the drug at 1:1 ratio. Hence, molar ratio of 1:1 of piroxicam:sucralose was considered as best stoichiometric ratio for co-crystal formation and selected for further studies.

The prepared co-crystals were incorporated into mucoadhesive buccal films prepared with various

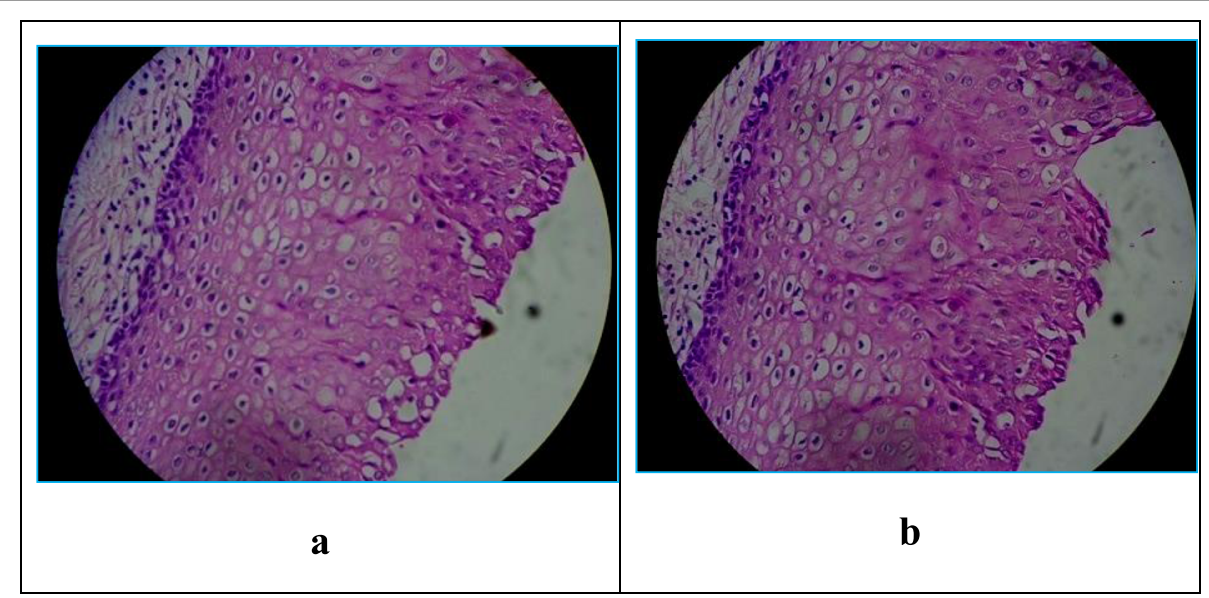

Fig. $\mathbf{6}$ Histopathological images of a normal mucosa and $\mathbf{b}$ mucosa exposed to formulation 
Table 6 Results of stability testing of piroxicam co-crystal buccal films at room temperature

\begin{tabular}{lllllll}
\hline Parameters & F1 & F2 & F3 & F4 & F5 & F6 \\
\hline Folding endurance & $286.33 \pm 1.52$ & $293.66 \pm 2.18 \pm 2.18$ & $291.00 \pm 1.04$ & $286.66 \pm 1.74$ & $279.66 \pm 1.52$ & $286.00 \pm 1.35$ \\
\% drug content & $95.98 \pm 1.25$ & $94.45 \pm 1.35$ & $93.85 \pm 2.01$ & $96.74 \pm 2.32$ & $93.65 \pm 1.45$ & $92.54 \pm 1.52$ \\
$\%$ CDR & $87.74 \pm 1.27$ & $88.69 \pm 1.52$ & $84.26 \pm 1.07$ & $81.32 \pm 1.29$ & $83.69 \pm 1.86$ & $86.35 \pm 1.67$ \\
\hline
\end{tabular}

polymers. All the formulations were smooth and elegant. Weight variation and thickness of prepared films were within acceptable limits. Results obtained from \% moisture uptake and \% moisture loss showed good sustainability of the films in different moisture conditions. Percent drug content of the films were within the range of $93.15 \pm 2.90$ to $96.88 \pm 0.08$. Tests of folding endurance and tensile strength have revealed that the films possess good flexibility and mechanical strength [35]. The surface $\mathrm{pH}$ of prepared formulations were ranging in between $6.29 \pm 0.07$ and $6.82 \pm 0.06$, i.e., nearer to salivary $\mathrm{pH}$ ( $\mathrm{pH} 6.8)$, indicating physiologically compatibility of prepared films thus lesser chances of mucosal irritation due to film. The mucoadhesive strengths of the formulations were increased with increase in quantity of polymers. The films containing carbopol 934 exhibited more mucoadhesive strength than those films containing chitosan. Cabopol 934 is a cross-linked polyacrylate polymer consisting of large number of carboxylic acidic groups having tendency to form hydrogen bonding with oligosaccharide chains in mucosal tissue. This may be reason for the higher values of mucoadhesive strength of carbopol [36, 37]. Swelling indices of the films were within range of $12.12 \pm 1.24 \%$ to $23.04 \pm 1.25 \%$ which is a prerequisite for release of the drug from films.

All the formulations were following first order release kinetics with $R^{2}$ value ranging in between 0.994 and 0.998 indicating concentration dependent drug release. Ex vivo drug permeation (F2) was found to be $84.74 \%$. The formulation F2 is consisting of chitosan, which is well known for its penetration enhancing power thus based on in vitro drug release and ex vivo drug permeation study it can be inferred that absorption of the drug is solubility limited and not permeability limited. In order to investigate the safety of the formulations to biological tissues, histopathological study plays a crucial role. The intactness of buccal mucosa without any cellular damage after $8 \mathrm{~h}$ of exposure to the formulation has revealed the safety of the formulation. The stability study has revealed that there is no any significant variation in studied parameters of the formulations after 3 months of storage at $40{ }^{\circ} \mathrm{C} \pm 2{ }^{\circ} \mathrm{C}$ and $75 \pm$ $5 \% \mathrm{RH}$. These results suggest that the formulations are stable for long term storage.

\section{Conclusion}

Mucoadhesive buccal films of piroxicam co-crystals were successfully prepared and evaluated. Co-crystals prepared with sucralose have highest (five-fold) solubility enhancement as compared to other co-formers. The formulation F2 has shown $84.74 \%$ drug permeation during ex vivo permeation study through goat buccal mucosa. Histopathological study witnessed the safety of the films. Based on the present study, it can be proposed that the co-crystallization technique is an effective technique for solubility enhancement of piroxicam. Further co-crystalloaded buccal patches could be a safer and effective formulation approach for improvement of therapeutic efficacy of drug.

\section{Abbreviations}

BCS: Biopharmaceutical Classification System; FTIR: Fourier transform infrared; DSC: Differential scanning colorimetry; API: Active pharmaceutical ingredient; NSAID: Non-steroidal anti-inflammatory drug; UV: Ultraviolet

\section{Acknowledgements}

Authors would like to thank the Principal of KLES College of Pharmacy, Nipani, for providing necessary facilities to carry out the research work. We hereby transfer, assign, or otherwise convey all copyright ownership, including any and all rights incidental thereto, exclusively to the journal, in the event that such work is published by the journal.

\section{Authors' contributions}

All authors (AA, RP, KA, and HR) have contributed for successfully completing the research work. All authors have read and approved the manuscript. KA, the corresponding author, has designed and monitored the study and approved the manuscript from all co-authors. AA has compiled the data and drafted the manuscript. RP has executed the research work and analyzed the results. HR has assisted in interpretation of the data and substantially revised the manuscript. All authors read and approved the final manuscript.

Funding

Not applicable—self-funded

Availability of data and materials

All data and materials are available on request

Ethics approval and consent to participate

Not applicable-in vivo study is not involved.

Consent for publication

Not applicable

Competing interests

The authors declare that they have no any competing interests.

Received: 24 February 2020 Accepted: 7 May 2020

Published online: 25 May 2020

References

1. Shewale S, Shete AS, Doijad RC, Kadam SS, Patil VA, Yadav AV (2015) Formulation and soild state characterization of nicotinamide based cocrystals of fenofibrate. Indian J Pharm Sci 77(3):328

2. Qiao N, Li M, Schlindwein W (2011) Pharmaceutical cocrystals: an overview. Int J Pharm 419:1-11

3. Nanda A, Kumar S (2017) Pharmaceutical Cocrystals: An Overview. Indian J Pharm Sci 79(6):858-871 
4. Miroshnyk I, Mirza S, Sandler N (2009) Pharmaceutical co-crystals - An opportunity for drug product. Exp Opin Drug Del 6(4):333-341

5. Joshi R, Raje S, Akram W, Garud N (2019) Particle engineering of fenofibrate for advanced drug delivery system. Future J Pharm Sci 5(14):1-11

6. Pandey NK, Sehal HR, Garg V (2017) Stable Co-crystals of Glipizide with Enhanced Dissolution Profiles: Preparation and Characterization. AAPS Pharm Sci Tech 18:2454-2465

7. Childs SL, Kenneth $\mathbb{H}$ (2007) Cocrystals of piroxicam with Carboxylic Acids. Cryst Growth Des 7(7):1291-1304

8. Garg V, Singh H, Bhatia A (2017) Systematic development of transethosomal gel system of piroxicam: Formulation optimization, in vitro evaluation, and ex vivo assessment. AAPS PharmSciTech 18(1):58-71

9. Shidhaye SS, Thakkar PV, Dand NM (2010) Buccal Drug Delivery of Pravastatin Sodium. AAPS Pharm Sci Tech 11:416-424

10. Mane PP, Bushetti SS, Keshavshetti GG (2014) Development and in-vitro evaluation of mucoadhesive buccal films of nebivolol. Indian J Pharm Sci 76(2):166-169

11. Adhikari SNR, Nayak BS, Nayak AK (2010) Formulation and Evaluation of Buccal Patches for Delivery of Atenolol. AAPS Pharm Sci Tech 11:1038-1044

12. Prasad RV, Gadekar RM, Madan JR (2012) Pharmaceutical Cocrystallization: A Review. Inter J Pharm and Chem Sci 1(3):1074-1085

13. Yadav S, Gupta PC, Sharma N (2015) Cocrystals : An alternative approach to modify physicochemical properties of drugs. Int Jour Pharm Chem Bio Sci 5(2):427-436

14. Pekamwar SS, Gadade D, Kale GK (2016) Co-crystalization: technique for improvement of pharmaceutical properties. Indian Drugs 53(9):5-11

15. Parmar VK, Shah SA (2013) Hydrochloride salt co-crystals: preparation, characterization and physicochemical studies. Pharm Dev Technol 18(2):443-453

16. Arafa MF, El-Gizawy SA, Osman MA (2016) Sucralose as co-crystal co-former for hydrochlorothiazide: development of oral disintegrating tablets. Drug Dev Ind Pharm 42(8):1225-1233

17. Puri D, Bhalekar MR, Sethi SS (2010) Evaluation of oral fast disintegrating tablet of taste masked famotidine in rat. Lat Am J Pharm 29(6):948-954

18. Vasantha PV, Puratchikody A, Mathew ST, Balaraman AK (2011) Development and characterization of Eudragit based mucoadhesive buccal patches of salbutamol sulfate. Saudi Pharm J 9(4):207-214

19. Karki S, Kim H, Na SJ (2016) Thin Film as an emerging platform for drug delivery. Asian J Pharm Sci 11(5):559-574

20. Bala R, Sharma S (2018) Formulation optimization and evaluation of fast dissolving film of aprepitant by using design of experiment. Bull Faculty Pharm Cairo Univ 56:159-168

21. Madhavi BR, Murthy VSN, Rani AP, Kumar GD (2013) Buccal film drug delivery system-An innovative and emerging technology. J Mol Pharm Org Process Res 1(107). https://doi.org/10.4172/2329-9053.1000107

22. Kempwade AA, Taranalli AD (2014) Formulation and evaluation of thermoreversible, mucoadhesive in situ intranasal gel of rizatriptan benzoate. J Sol-Gel Sci Technol 72:43-48

23. Shah RA, Mehta MR, Patel DM, Patel CN (2011) Design andoptimization of mucoadhesive nasal in situ gel containing sodiumcromoglycate using factorial design. Asian J Pharm 5(2):65-74

24. Abu-Huwaij R, Obaidat RM, Sweidan K, Al-Hiari Y (2011) Formulation and in vitro evaluation of xanthan gum or carbopol 934-based mucoadhesive patches loaded with nicotine. AAPS Pharm Sci Tech 12(1):21-27

25. Nair AB, Kumria R, Harsha S, Attimarad M, Al-Dhubiab BE, Alhaider IA (2013) In vitro techniques to evaluate buccal films. J Control Release 166(1):10-21

26. Augusthy AR, Vipin KV, Sarath CC, Thushara MV, Shahin MTK (2014) Formulation and Evaluation of Mucoadhesive Buccal Film of Lisinopril. Res Rev J Pharm Nano 2(1):45-51

27. Schultheiss N, Newman A (2009) Pharmaceutical cocrystals and their physicochemical properties. Cryst Growth Des 9:2950-2967

28. Shan N, Zaworotko MJ (2008) The role of cocrystals in pharmaceutical sciences. Drug Discov Today 13:440-446

29. Aakeroy CB, Salmon DJ (2005) Building cocrystals with molecular sense and supramolecular sensibility. Cryst Eng Comm 7(72):439-448

30. Horst JHT, Deji MA, Cains PW (2009) Discovering new cocrystals. Cryst Growth Des 9(3):1531-1537

31. Aitipamula S, Banerjee R, Bansal AK, Biradha K, Cheney ML, Choudhury AR et al (2012) Polymorphs, salts and cocrystals:What's in a name? Cryst Growth Des 12:2147-2152

32. Etter MC (1990) Encoding and decoding hydrogen-bond patterns of organic compounds. Acc Chem Res 23:120-126
33. Yamashita H, Hirakura Y, Yuda M, Terada K (2014) Coformer screening using thermal analysis based on binary phase diagrams. Pharm Res 31(8):1946-1957

34. Tomaszewska I, Karki S, Shur J, Price R, Fatoki N (2013) Pharmaceutical characterization and evaluation of co-crystals: importance of in vitro dissolution conditions and type of conformer. Int J Pharm 453:380-388

35. Nafee NA, Boraie MA, Ismail FA, Mortada LM (2003) Design and characterization of mucoadhesive buccal patches containing cetylpyridinium chloride. Acta Pharma 53(3):199-212

36. Rasaya SR, Mijithiya RJ, Ghosh PK, Umrethia ML (2006) Thermoreversible mucoadhesive gel for nasal delivery of sumatriptan. AAPS Pharm Sci Tech 7(3):E1-E7

37. Yehia SA, El-Gazayerly ON, Basalious EB (2009) Fluconazole mucoadhesive buccal films: in vitro/in vivo performance. Curr Drug Deliv 6(1):17-27

\section{Publisher's Note}

Springer Nature remains neutral with regard to jurisdictional claims in published maps and institutional affiliations.

\section{Submit your manuscript to a SpringerOpen ${ }^{\circ}$ journal and benefit from:}

- Convenient online submission

- Rigorous peer review

- Open access: articles freely available online

High visibility within the field

- Retaining the copyright to your article

Submit your next manuscript at $\boldsymbol{\nabla}$ springeropen.com 